\title{
Improving Student Engagement Via Content Personalization
}

\section{Dr. Christopher D. Schmitz, University of Illinois}

Dr. Christopher Schmitz was born in Pana, Illinois in 1969. Pana Senior High valedictorian in 1988, he went on to receive his B.S. with university honors and M.S. (fault-tolerant adaptive systems) in ECE from the University of Illinois. In 1995, he joined TRW Space and Electronics Group in the areas of satellite communication and antenna systems before returning to the University of Illinois in 1997. There, he completed his Ph.D. in the area of multiuser communication in 2002. As an academic professional, he investigated multiple-microphone hearing systems and wireless hearing system links from 2002 to 2008 and served as a visiting lecturer from 2005 to 2011 at the university. His research interests are in adaptive digital signal processing, digital communications, and education pedagogy. He currently serves the ECE department of his alma mater as lecturer, research specialist, and chief undergraduate advisor.

\section{Prof. Michael C. Loui, University of Illinois, Urbana-Champaign}

Michael C. Loui is a professor of Electrical and Computer Engineering and University Distinguished Teacher-Scholar at the University of Illinois at Urbana-Champaign. His interests include computational complexity theory, professional ethics, and the scholarship of teaching and learning. He serves as editor of the Journal of Engineering Education and as a member of the College Teaching and Accountability in Research editorial boards. He is a Carnegie scholar and an IEEE fellow. Professor Loui was associate dean of the Graduate College at Illinois from 1996 to 2000. He directed the theory of computing program at the National Science Foundation from 1990 to 1991. He earned the Ph.D. at M.I.T. in 1980.

Renata A Revelo Alonso, University of Illinois, Urbana-Champaign 


\section{Improving Student Engagement Via Content Personalization}

\section{Introduction}

For about ten years, the department of Electrical and Computer Engineering at the University of Illinois at Urbana-Champaign has offered a four-credit course each semester on digital information technologies, ECE101: Exploring Digital Information Technology. This is a course tailored towards students in non-STEM disciplines, such as economics, graphic design, political science, theatre, accountancy, music performance, new media, and advertising. The course satisfies two general education requirements for these students.

A general education course in engineering can be challenging to teach because non-engineering students have widely-varying levels of scientific knowledge, mathematical abilities, programming skills, and technology experiences. Consequently, if the course aims at the "average" student, many students will find the course material either too easy or too difficult. Worse yet, when the material seems irrelevant, as it often will to the non-STEM majors, students are likely to become disengaged.

This diverse group of students leads to a quandary while teaching, namely how to keep all the students challenged in a way appropriate to their level of expertise and maintain their interest when the material deviates from what they may have expected from the course. While we believe the material to be highly relevant to a broad range of disciplines, the direct relevance may be often difficult for the students, the teaching assistants, and even the instructor to discern.

In this study, we investigated whether we could maintain student interest by using students' previous experiences to personalize the course material throughout the semester. When students find the course material relevant to their own interests, they are likely to become engaged and to achieve deep learning. ${ }^{1}$ By continually applying the course topics towards personal interests, the students are primed to tackle a final project where they are encouraged and guided while applying their skills to a project of personal interest.

To personalize the course material, we pose a general question to the students, evaluate their answers, and then hopefully convert one or more answers into an example, assignment, or exam question that applies the course knowledge in a nontraditional way that is relevant to students' interests. For example, the students may be asked to provide an example of where they have needed to summarize information for decision making. Later, their answers to the summarization question are used to investigate mathematical means of compression often applied to sound, video, or general file systems.

Notable difficulties in personalizing course content then include how to extract relevant and interesting applications from 30 to 60 students, and how to manage the time required to map these applications into the course. We will address time management first, under the section "Course Structure", the method of seeking applications second in "Examples", and observations of possible outcomes in "Assessment". 


\section{Course Structure}

Instructors might ask, "How much time does content personalization take?" and "Is this sustainable in any course?" and "Does this require a heroic effort by the instructor?". All of these questions suggest that the course must be carefully structured to support the personalization method. We feel that community, cooperation, and accountability can help in implementing content personalization. When students feel a sense of community, they are more likely to share insights and excitement regarding the applications of the material. They are also likely to cooperate in helping each other learn, for example, by answering one another's questions. Consequently, encouraging cooperation among students can decrease the time required for the instructor to provide one-on-one teaching to students who have difficulty with the course. Finally, individual accountability can also increase the feeling of community and encourage the cooperative action of the students.

Community often comes naturally in a classroom of 30 or fewer students. A small lab section of eight to ten students further enhances this feeling of community. Unfortunately, it may take the majority of a semester for the feeling of community to fully materialize and, for larger class sizes, it may not materialize at all. In fact, there seems to be a class size beyond which the students are more likely to depend upon only a single partner and less likely to form friendships between lab teams.

To facilitate the growth of community among all students in the course, we have often utilized web forums and/or wiki pages where students can interact with each other in answering openended questions, forming project ideas, and even making recommendations on project solutions. We have varied the amount of oversight on these tools and found that a handful of directed (and graded) assignments are necessary for any participation and that regular weekly assignments are necessary for near $100 \%$ participation.

Cooperative action can be encouraged by allowing handwritten assignments to carry the names of two or three students. Although many instructors may be concerned with cheating in these situations, a good balance between lab and exam grades within the grade book often has the desired effect of sifting the hitchhikers from the contributors. In the spring of 2011, we finished mapping our assignments to an online homework manager. Although the students were still encouraged to work together, the individual submission of online assignments led students to feel that the work should be tackled independently. In that single act, we found that the level of community within the class had dropped precipitously and had to be augmented by other means. A few handwritten assignments were re-introduced to the class as were the forums and wikis mentioned above. We also recruited assistance from previous students who are both willing and excited to return to aid current student during open lab hours. The use of prior students may be extended to supervised study sessions.

To an instructor, holding the students accountable typically means holding them to high standards in the grade book based on homework assignments and exams. In reality, it can mean much more, as discussed above, since our course goals include not only mastery of coursespecific knowledge, but also the deeper understanding and application of the material in varied contexts of student interest. Students do respond readily when a course grade is on the line, even 
when the effect may be rather small on the whole. Therefore, participation grades are an effective means of holding the students accountable for completing the actions necessary for building community and active cooperation as well as for answering the questionnaires used for content personalization.

The flip-side of student accountability is instructor accountability. If the instructor expects the students to actively participate in a class founded on content personalization that includes their active participation in building community and working cooperatively, the instructors should also hold themselves to a higher level of accountability. The content provided by the students must be mapped back into the classroom in regular and predictable manner so that the students regularly experience the merits of their efforts. It cannot be done only when time permits. The instructor must rely on the course structure to provide a couple of extra hours per week that must be devoted to these tasks.

\section{Examples}

At first, we sought course-personalization applications only during project discussions near the semester's end. Later, we gathered ideas through questionnaires administered through a learningmanagement system (LMS). More recently, we embedded the questionnaires within one-minute papers $^{2}$ administered at the end of most lectures; these one-minute papers also served to record attendance. The participation reached nearly $100 \%$, yet not every question generated suitable answers.

In the first week of the semester, we asked the students, "Name something that you would like to see automated." The answers submitted varied, but a majority referenced some form of home automation. In the next class session, we briefly discussed the state-of-the-art in home automation. Two months later, we revisited a specific answer from that questionnaire, "Pointing a finger or twirling it and the fan starts or speeds [up]". This was suggested back to the class as a potential topic for the final project: perhaps a laser pointer could be used to control a ceiling fan. It was not uncommon for a single questionnaire or even a single answer from a questionnaire to produce multiple examples or exercises in the same semester.

It the fourth week of the semester, we asked students, "Provide an example of something that is in 'harmony', then give a definition of the term harmony that is consistent with your example". One student answered, "A well-designed object, such that a graphic designer would seek to make, can be described as harmonious. This means that all of its elements play off each other in an ideal way". This student's answer provides a perfect example of how course personalization can have exactly the intended effect. The course topic on harmony generally discusses the addition of time-domain, periodic signals analogous to those that might be produced by musical instruments and discusses harmony in terms of the mathematical principles of the periods and fundamental frequencies of the composing signals, i.e., Fourier analysis. Although Fourier analysis of musical sounds is a traditional topic for a course for non-STEM students ${ }^{3,4}$, this student answer challenged us to propose a novel assignment. A quick Internet search for "harmonic image" led us to a photograph of United States of America flags hanging from balconies at various distances (www.harmonicimage.com/sitebuildercontent/sitebuilderpictures/ramdom/insideFVPG.jpg). 
While this image would be in-arguably described as harmonious, it could also be analyzed mathematically.

You were asked: Provide an example of something that is in harmony, then give a definition of the term that is consistent with your example.

You answered: A well-designed object, such that a graphic designer would seek to make, can be described as harmonious. This means that all of its elements play off each other in an ideal way.

Harmonics in Images:

Consider the image above as a reference only (not to be mathematically equivalent to this question). Suppose the flags hanging on the first balcony have 6 stripes per inch and the flags hanging from the second balcony have 8 stripes per inch. What is the period of repetition in inches of both rows of flags when taken together?

This realization, when proposed to the students in the form of this assignment, should broaden their expectations of how far the material might be extended. Indeed, in our classroom, it raised discussions of frequency-domain representations of images, of numerical measures of harmony in everyday items, and, later, of the method of JPEG compression for images. This single student response has provided a non-standard application of interest to a large host of non-STEM students valid for semesters to come and shows that time committed to the method of content personalization can have a cumulative effect on the course.

\section{Assessment}

We are assessing levels of students' engagement and gathering data about students' ability and determination to continue applying their knowledge in the years after they complete the course. We have found that interviewed students showed persistence in the course even when they had great apprehension early on. These students also commented positively on the course's hands-on experiences such as the final project.

The HTML that we did cover was very simple, you know like making a paragraph that is formatted with a heading, that is different than the paragraph, but it shows you where to go to improve upon that, which was really nice. It gave you the skills to just kind of start on your own. (Student 8)

I also improved on like hardware stuff. Recently I learned how to fix my fan on my MacBook which saved a lot of money for me. I wouldn't even have done that unless I didn't have some previous background in doing hardware in which we did in class... I was able to like fix my fan not because they taught me that but because they really broke it down so that you could understand that a lot of things are just that you take it a step at a time. (Student 11) 
The majority of students said that the final project increased their confidence about tackling future technical projects either on their own or through other courses. As above, many of the comments specifically say that it is not necessarily the specific technical skill taught, but the encouragement to take the material beyond to other applications. Many of the interviewed students said that practical laboratory and Web development skills were important in their professional careers. Finally, it should be noted that the majority of the interviewed students cited their professor and TAs as important aspects of their experience in the course in future semesters.

\section{References}

1. Barkley, E. F. (2010). Student engagement techniques: A handbook for college faculty. San Francisco: Jossey-Bass.

2. Angelo, T.A., and Cross, K.P. (1993). Classroom Assessment Techniques, 2nd ed. San Francisco: JosseyBass. pp. 148-153.

3. Kuc, R. (2001). Teaching the nonscience major: EE101-The digital information age. IEEE Transactions on Education, 44 (2), 158-164.

4. Orsak, G. C., Wood, S. L., Douglas, S. C., Munson, D. C., Treichler, J. R., Athale, R. A., and Yoder, M. W. (2004)._Engineering our digital future: The Infinity Project. Prentice Hall. 